\title{
Copper-Catalyzed Difluoromethylation of Alkyl Halides Enabled by Aryl Radical Activation of Carbon-Halogen Bonds
}

\author{
Aijie Cai, Wenhao Yan, and Wei Liu* \\ Department of Chemistry, University of Cincinnati, Cincinnati, Ohio, 45221, United States
}

\begin{abstract}
The engagement of unactivated alkyl halides in copper-catalyzed cross-coupling reactions has been historically challenging, due to their low reduction potential and the slow oxidative addition of copper(I) catalysts. In this work, we report a novel strategy that leverages the halogen abstraction ability of aryl radicals, thereby engaging a diverse range of alkyl iodides in copper-catalyzed Negishi-type cross-coupling reactions at room temperature. Specifically, aryl radicals generated via copper catalysis efficiently initiate the cleavage of the carboniodide bonds of alkyl iodides. The alkyl radicals thus generated enter the copper catalytic cycles to couple with a difluoromethyl zinc reagent, thus furnishing the alkyl difluoromethane products. This unprecedented Negishi-type difluoromethylation approach has been applied to the late-stage modification of densely functionalized pharmaceutical agents and natural products.
\end{abstract}

\section{Introduction}

The efficient development of new medicines that treat and prevent diseases plays a vital role to improve the quality of human life. Seminal work by Lovering has shown that increasing fraction of $\mathrm{sp}^{3}$ hybridized carbons correlates with the clinical success of drug candidates. ${ }^{1,2}$ Therefore, the selective construction of $\mathrm{sp}^{3}$-enriched centers is among the most important reactions. In the arsenal of organic chemists, transition metalcatalyzed cross-coupling of unactivated alkyl halides with organometallic reagents remains one of the most straightforward and modular approaches to the connection of $\mathrm{sp}^{3}$-hybridized carbons. ${ }^{3-6}$ Tremendous progress has been made in this area through the use of palladium, ${ }^{7-10}$ and, more recently, nickel catalysts. ${ }^{11-15}$

On the other hand, copper catalysts represent appealing alternatives to their palladium and nickel counterparts. ${ }^{16-24}$ As copper is one of the most abundant transition metals in Earth's crust, it is much less expensive and more globally available than $\mathrm{Pd}$ and $\mathrm{Ni}\left[\right.$ e.g., $\mathrm{Cu}(\mathrm{OAc})_{2}<\$ 1 / \mathrm{g}, \mathrm{Ni}(\mathrm{OAc})_{2}$ ca. $\$ 10 / \mathrm{g}$, and $\mathrm{Pd}(\mathrm{OAc})_{2}$ ca. $\left.\$ 80 / \mathrm{g}\right]{ }^{25}$ In addition, being an essential trace element vital to the health of humans and other living organisms, ${ }^{26-29}$ copper salts typically have low toxicity and little environmental impact, as indicated by the higher permitted daily exposure values $(\mathrm{Cu} 3400 \mu \mathrm{g}$, Ni $220 \mu \mathrm{g}$, and $\mathrm{Pd} 100 \mu \mathrm{g}){ }^{30}$

Despite these prominent economic and environmental features, the engagement of unactivated haloalkanes in coppercatalyzed cross-coupling reactions remains challenging. The main difficulty associated with such processes has been attributed to the sluggish two-electron oxidative addition of copper(I) complexes. In addition, the low reduction potential of unactivated alkyl halides ( $E_{\text {red }}<-2 \mathrm{~V}$ vs SCE) hinders the direct single electron transfer (SET) from $\mathrm{Cu}^{\mathrm{I}}$ catalysts. By contrast, the capture of alkyl radicals by $\mathrm{Cu}^{\mathrm{II}}$ species and the ensuing reductive elimination of the organocopper(III) complexes can proceed efficiently (Figure 1a).

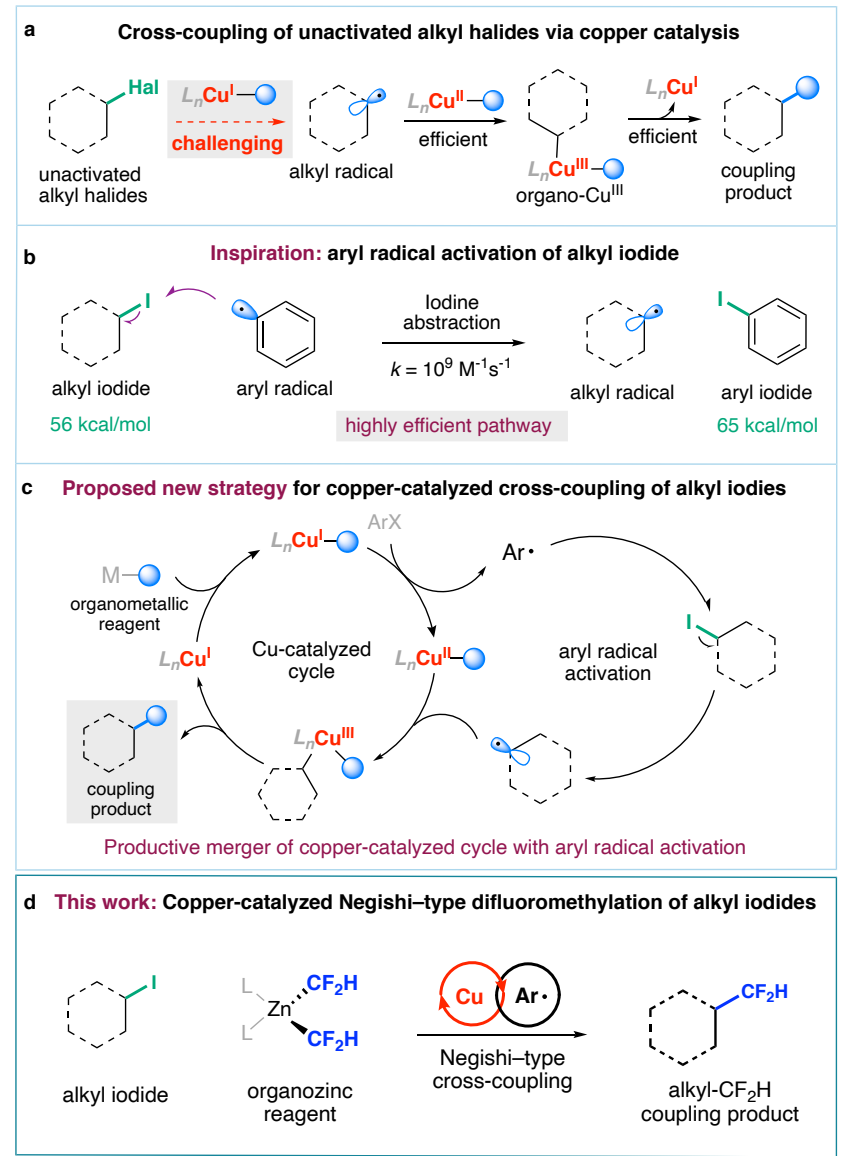

Figure 1. The aryl radical activation pathway can enable a new approach for copper-catalyzed cross-coupling of unactivated alkyl halides. Ar·, aryl radical.

Given the efficiency of the radical capture and reductive elimination steps, strategies relying on the formation of alkyl radicals have been recently applied to engage alkyl halides in copper catalysis. Thus, Fu and Peters have developed photoinduced approaches to the generation of excited-state $\mathrm{Cu}$ nucleophile species, which could reduce alkyl halides via SET pathways. ${ }^{31-35}$ The MacMillan group has pioneered the use of silyl radicals, generated via photoredox catalysis, for the activation of alkyl halides in copper catalysis. ${ }^{36-38}$ More recently, 
Leonori discovered that $\alpha$-aminoalkyl radicals could enable efficient copper-catalyzed amination of alkyl iodides. ${ }^{39,} 40$ Despite these advances, a general activation mode that can allow for the coupling of unactivated alkyl halides with mild organometallic reagents, e.g., alkylzinc reagents, via copper catalysis remains highly desirable.

It is well-precedented that aryl radicals are capable of abstracting iodine atoms from alkyl iodides to form alkyl radicals and aryl iodides with a rate constant of $k=10^{9} \mathrm{M}^{-1} \mathrm{~s}^{-1}$ (Figure 1b) ${ }^{41}$ The iodine abstraction step is expected to be irreversible (rate constant of the reverse reaction $\left.k<10^{2} \mathrm{M}^{-1} \mathrm{~s}^{-1}\right)^{42}$ due to the difference in the bond dissociation energy (BDE) of the $\mathrm{C}\left(\mathrm{sp}^{2}\right)$ I bonds $(\mathrm{BDE}$ of iodobenzene $=65 \mathrm{kcal} / \mathrm{mol})$ and $\mathrm{C}\left(\mathrm{sp}^{3}\right)-\mathrm{I}$ bonds $(\mathrm{BDE}$ of isopropyl iodide $=56 \mathrm{kcal} / \mathrm{mol}){ }^{43}$ The high reactivity and irreversibility of the iodine abstraction step should outcompete other unwanted pathways of the aryl radicals, including the direct capture of aryl radicals by copper catalysts $\left(k \approx 10^{8} \mathrm{M}^{-1} \mathrm{~s}^{-1}\right) \cdot{ }^{44}$ Nonetheless, such a reactivity has received little attention in synthetic applications. ${ }^{45-47}$ We hypothesize that various alkyl iodides could be converted to alkyl radicals for copper catalysis via the use of the transient aryl radicals that could be readily generated via copper-catalyzed pathways, e.g., from arenediazonium salts. The SET to arenediazonium salts is a unique reactivity of $\mathrm{Cu}^{\mathrm{I}}$ complexes and has been widely involved in transformations of arenediazonium salts, including Sandmeyer reaction and Meerwein arylation. ${ }^{48}$ We postulate that such a productive merger of copper catalysis with aryl radical activation could provide a new strategy for the coupling of unactivated alkyl iodides with mild organometallic reagents (Figure 1c). As a proof of concept, in this work, we have exploited this new strategy to deliver a general approach to the difluoromethylation of alkyl iodides via a copper-catalyzed Negishi-type cross-coupling reaction (Figure 1d).

The incorporation of difluoromethyl $\left(\mathrm{CF}_{2} \mathrm{H}\right)$ groups into organic molecules has recently received increasing attention largely owing to their unique hydrogen bonding ability. ${ }^{49-57}$ Due to the highly polarized $\mathrm{C}-\mathrm{H}$ bond of the $\mathrm{CF}_{2} \mathrm{H}$ group - induced by the electron-withdrawing fluorine atoms - it can act as a lipophilic hydrogen bond donor. Recent studies showed that the hydrogen bonding ability of the $\mathrm{CF}_{2} \mathrm{H}$ group was comparable to that of hydroxyl, thiol, and amine groups. ${ }^{58,59}$ Therefore, the installation of $\mathrm{CF}_{2} \mathrm{H}$ groups has become a commonly used tactic in medicinal chemistry to modulate the lipophilicity and metabolic stability of lead drug candidates. ${ }^{60}$

One of the most straightforward approaches to the synthesis of $\mathrm{CF}_{2} \mathrm{H}$-containing compounds is the direct difluoromethylation of the corresponding organohalides. Although transition metal catalysis has received great success in the difluoromethylation of aryl halides, ${ }^{61-69}$ the analogous reaction with unactivated alkyl halides remains a formidable challenge. Prakash has reported a nucleophilic substitution approach to the conversion of primary alkyl halides to their corresponding difluoromethyl phenyl sulfones, which were then transformed to the alkyl difluoromethanes using the sodium/mercury amalgam reduction. ${ }^{70}$ Very recently, the Shen group has reported an elegant Pd-catalyzed approach for the difluoromethylation of primary alkyl halides with $\mathrm{TMSCF}_{2} \mathrm{H}$ as the $\mathrm{CF}_{2} \mathrm{H}$ source along with stoichiometric copper iodide. ${ }^{71}$ Nonetheless, the limitation to primary alkyl halides and the use of large quantity of copper salts might dampen the synthetic utilities of these methods. Given the known iodine abstraction ability of aryl radicals, we questioned whether the aryl radical activation approach could be applied to enable a catalytic $\mathrm{CF}_{2} \mathrm{H}-$ installation protocol with significant utility to medicinal chemistry. We disclose herein the successful execution of this strategy and report a broadly applicable protocol for the catalytic conversion of alkyl iodides to alkyl difluoromethanes.

\section{Results and Discussion}

The proposed mechanism for the aryl radical-enabled, copper-catalyzed difluoromethylation of alkyl iodides is outlined in Figure 2. We reason that the transmetallation of a $\mathrm{Cu}^{\mathrm{I}}$ catalyst 1 with a zinc-difluoromethyl reagent, (DMPU $)_{2} \mathrm{Zn}\left(\mathrm{CF}_{2} \mathrm{H}\right)_{2} 2$, i.e., Vicic-Mikami reagent, ${ }^{62,64}$ could form a $\mathrm{Cu}^{\mathrm{I}}-\mathrm{CF}_{2} \mathrm{H}$ species 3. Notably, a hectogram synthesis of $\mathbf{2}$ has been recently reported by Pfizer. ${ }^{72}$ Our previous work has suggested that $\mathrm{Cu}^{\mathrm{I}}-\mathrm{CF}_{2} \mathrm{H}$ species 3 was a strong reductant (cal'd $E_{\text {red }}=-1.2 \mathrm{~V}$ vs SCE). ${ }^{73-}$ ${ }^{75}$ Therefore, we anticipate that 3 could undergo a SET event with a diazonium salt $\mathbf{4}$ to form an aryl radical intermediate $\mathbf{5}$, with the concurrent formation of a $\mathrm{Cu}^{\mathrm{II}}-\mathrm{CF}_{2} \mathrm{H}$ complex $6 .^{76-78}$ The former should efficiently abstract an iodine atom from an alkyl iodide 7 to form an alkyl radical 8 and an aryl iodide 9. Oxidative capture of 8 by the $\mathrm{Cu}^{\mathrm{II}}-\mathrm{CF}_{2} \mathrm{H}$ species 6 would furnish a highvalent organocopper(III) complex $\mathbf{1 0},{ }^{79}$ which should undergo reductive elimination to afford the alkyl difluoromethane coupling product 11..$^{80-82}$ This reductive elimination step would regenerate the starting $\mathrm{Cu}^{\mathrm{I}}$ catalysts and close the catalytic cycle.

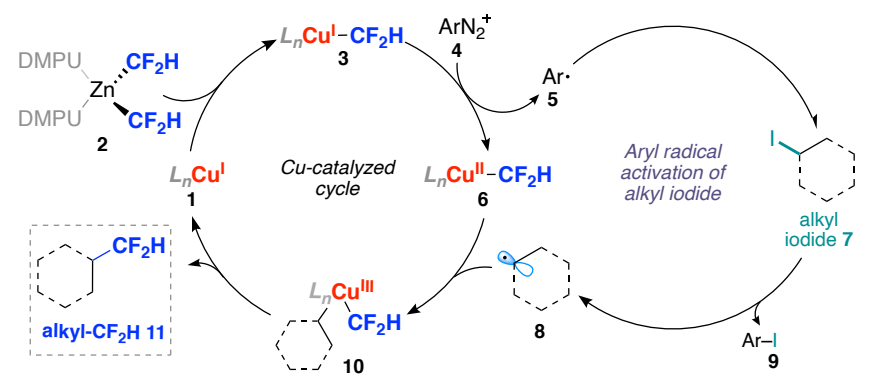

Figure 2. Proposed catalytic cycle for the aryl radical-enabled, copper-catalyzed coupling of alkyl iodides with $\mathrm{CF}_{2} \mathrm{H}$ groups.

\section{Reaction Optimization.}

This hypothesis was then tested on a model substrate 12 with a various combinations of different copper sources, ligands and arenediazonium salts (Table 1). We were delighted to find that when 2,4,6-trimethylbenzene diazonium salt $\mathbf{4 a}$ was used, 12 could efficiently couple with the difluoromethylzinc reagent 2 under copper-catalyzed conditions, affording the desired alkyl difluoromethane product $\mathbf{1 3}$ at room temperature (entry 1). The use of a sterically hindered and electron-rich diazonium salt 4a was crucial to the success of this reaction (entry 2 to 5). We reason that the electron-rich and sterically hindered aryl rings stabilized the aryl radicals, thereby preventing other undesired pathways. It is worth noting that $\mathbf{4 a}$ could be easily synthesized from the corresponding aniline (ca. $\$ 0.3 / \mathrm{g}$ ) on a decagram scale and be stored in a $-20^{\circ} \mathrm{C}$ freezer for at least a month without noticeable decomposition. Tridentate nitrogen ligand, terpyridine $\mathbf{L 1}$, was found to be beneficial for this reaction, while other bidentate ligands such as bipyridine $\mathbf{L 3}$ or phenanthroline L4 was less efficient (entry 6 to 8). We 
attribute this efficiency to the stabilization of the intermediate $\left[\mathrm{Cu}-\mathrm{CF}_{2} \mathrm{H}\right]$ species by tridentate ligands.

Table 1. Reaction optimization ${ }^{a}$

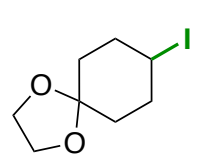

$$
\begin{gathered}
\mathrm{Cu}(\mathrm{OTf})_{2}(20 \mathrm{~mol} \%) \\
\stackrel{\text { L1 }(20 \mathrm{~mol} \%)}{\longrightarrow} \\
\text { diazonium salt 4a }
\end{gathered}
$$

\begin{tabular}{|c|c|c|}
\hline entry & Variation from standard & Yield $^{\mathrm{b}}$ \\
\hline 1 & None & $90 \%\left(99 \%{ }^{c}\right)$ \\
\hline 2 & $\mathbf{4 b}$ instead of $\mathbf{4 a}$ & $85 \%$ \\
\hline 3 & $\mathbf{4 c}$ instead of $\mathbf{4 a}$ & $68 \%$ \\
\hline 4 & $\mathbf{4 d}$ instead of $\mathbf{4 a}$ & $25 \%$ \\
\hline 5 & $4 e$ instead of $4 \mathbf{a}$ & $82 \%$ \\
\hline 6 & $\mathbf{L} 2$ instead of $\mathbf{L} \mathbf{1}$ & $78 \%$ \\
\hline 7 & $\mathbf{L 3}$ instead of $\mathbf{L} \mathbf{1}$ & $27 \%$ \\
\hline 8 & L4 instead of $\mathbf{L} \mathbf{1}$ & $17 \%$ \\
\hline 9 & {$[\mathrm{Cu}(\mathrm{OTf})]_{2} \cdot \mathrm{C}_{6} \mathrm{H}_{6}$ instead of } & $80 \%$ \\
\hline 10 & $\mathrm{Cu}(\mathrm{acac})_{2}$ instead of $\mathrm{Cu}(\mathrm{OTf})_{2}$ & $78 \%$ \\
\hline 11 & open to air & $86 \%$ \\
\hline 12 & $4 \mathbf{a}$ (1.5 equiv.) & $74 \%\left(83 \% \%^{c}\right)$ \\
\hline 13 & $\mathbf{4 a}$ (2.0 equiv.) & $84 \%\left(92 \% \%^{c}\right)$ \\
\hline 14 & no $\mathrm{Cu}(\mathrm{OTf})_{2}$ & N.D. \\
\hline 15 & no $4 \mathbf{a}$ & N.D. $\left(<5 \%{ }^{\mathrm{c}}\right)$ \\
\hline
\end{tabular}

DMSO, r.t, $1 \mathrm{~h}$

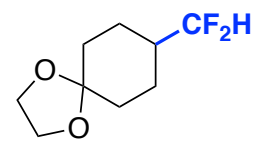

13

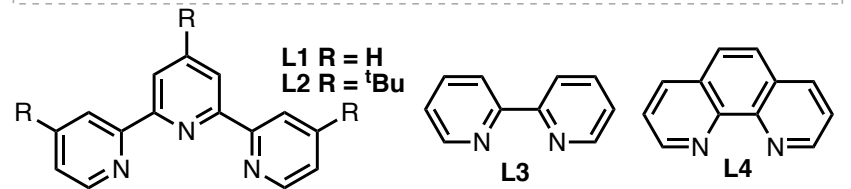

${ }^{a}$ Reactions were conducted with 12 ( 0.1 mmol, 1.0 equiv.), diazonium salt ( $0.25 \mathrm{mmol}, 2.5$ equiv. $), 1$ ( $0.15 \mathrm{mmol}, 1.5$ equiv.) $\mathrm{Cu}(\mathrm{OTf})_{2}(20 \mathrm{~mol} \%)$, and ligand $(20 \mathrm{~mol} \%)$ in DMSO $(0.6 \mathrm{~mL})$ at R.T. ${ }^{b}$ Yields were determined by ${ }^{19} \mathrm{~F}$ NMR using $1-$ fluoro-3-nitrobenzene as the internal standard. ${ }^{\mathrm{c} C o n v e r s i o n}$ of 12, determined by GC using 1-fluoro-3-nitrobenzene as the internal standard. N.D., not detected.

Other copper(I) and copper(II) salts could also be used as the catalysts (entry 9 and 10). Notably, the use of less airsensitive copper(II) catalysts allowed the reaction to be set up under an air atmosphere affording $\mathbf{1 3}$ in a similar yield (entry 11). The copper(II) salts were expected to be reduced in situ by the organozinc reagents to form the active copper(I) catalysts. Moreover, the loading of the diazonium salts could be reduced while the desired product was formed in good yields (entry 12 and 13), although our later study revealed that unreacted alkyl iodides occasionally complicated the purification of difluoromethylated products. Therefore, 2.5 equiv. of $4 \mathbf{a}$ was used in the entire study to ensure the full consumption of the alkyl iodides. Finally, control experiments have shown that no desired products were formed in the absence of either the diazonium salt or the copper catalyst (entry 14 and 15). The alkyl iodide remained intact when the diazonium salt was omitted in the reaction, consistent with the argument that copper catalysts alone were not reactive toward unactivated alkyl iodides.

\section{Substrate Scope}

With the optimized conditions in hand, we then evaluated the group tolerance of this aryl radical activation strategy (Table 2). A broad range of secondary alkyl iodides appended to a variety of rings (cyclobutane, cyclopentane, cyclohexane, piperidine, 1,3-dioxane, azetidine, and azepane) afforded the corresponding $\mathrm{CF}_{2} \mathrm{H}$ products in good to excellent yields (13 to $\mathbf{2 4}, 50 \%$ to $90 \%$ yield). Functional groups including acetal, carbamate, ester, and even tertiary amine could be tolerated under the reaction conditions. A high diastereoselectivity was observed for the difluoromethylation of the alkyl iodide derived from menthol $(\mathbf{1 8}$, d.r. $=16: 1)$, presumably induced by the interaction between the bulky isopropyl group and the copper(II) complex during the radical recombination step. Acyclic secondary alkyl iodides, some of which contained reactive hydrogen atoms that were prone to $\beta$ hydride elimination reactions, were successfully difluoromethylated (25 to $\mathbf{2 8}, 60$ to $77 \%$ yield). By contrast, previously reported decarboxylative and deaminative difluoromethylation reactions were incapable of installing $\mathrm{CF}_{2} \mathrm{H}$ groups at acyclic alkyl sites..$^{73,74}$

Next, the compatibility of primary alkyl iodides has been evaluated. Substrates that contain diverse functional groups, such as silyl ether, sulfonamide, imide, perfluoroalkyl, and the base-labile Fmoc group, were found to give good to excellent yields of the desired products (29 to $35,56 \%$ to $88 \%$ yield). Alkyl and aryl bromides were accommodated under the reaction conditions (36 and $\mathbf{3 7}, \mathbf{6 7 \%}$ and $82 \%$ yield, respectively), providing potential opportunities for the diversification of the difluoromethylated products. A substrate that contained an aryl iodide moiety could be selectively activated at the $\mathrm{C}\left(\mathrm{sp}^{3}\right)$ site with 1.3 equiv. of diazonium salt being employed (38, $59 \%$ yield); the use of more diazonium salts led to the protodeiodination of the aryl iodide group, indicating a competing iodine abstraction from the aryl ring $\left(k=9 \times 10^{7} \mathrm{M}^{-}\right.$ $\left.{ }^{1} \mathrm{~s}^{-1}\right){ }^{83,}{ }^{84}$ Notably, unprotected phenol and aldehyde groups, which were typically problematic in cross-coupling reactions involving reactive organometallic reagents, did not interfere the difluoromethylation reactions (39 and 40, 92 and 91\% yield, respectively). An electron-rich aromatic ring, which was prone to arylation with aryl radicals in the Gomberg-Bachmann reaction, ${ }^{85}$ was well tolerated $(41,85 \%$ yield). Substrates that contained potential nucleophiles, such as unprotected indole and terminal alkyne, which were known to react with alkyl iodides under related conditions ${ }^{35,39}$, could furnish the desired products in reasonable yields (42 and $\mathbf{4 3}, 49 \%$ and $42 \%$, respectively). Difluoromethylation of alkyl iodides that consisted of pharmaceutically relevant heterocycles, including thiophene, oxazole, thiazole, and pyridine, was accomplished in generally good efficiency. (44 to $47,46 \%$ to $69 \%$ yield). Finally, the 
scalability of this protocol has been demonstrated with the synthesis of compound $\mathbf{3 2}$ in a $5 \mathrm{mmol}$ scale (65\% yield). 
Table 2. Substrate Scope of the Aryl Radical-Enabled, Copper-Catalyzed Difluoromethylation of Alkyl Iodides ${ }^{a}$

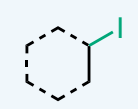

alkyl iodide
${ }^{\text {DMPU }}{ }^{-}{ }^{\prime} n^{-\mathrm{CF}_{2} \mathrm{H}}$

organozinc reagent

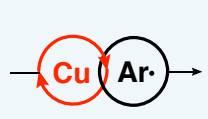<smiles>FC(F)(F)C1CCCCC1</smiles>

alkyl- $\mathrm{CF}_{2} \mathrm{H}$

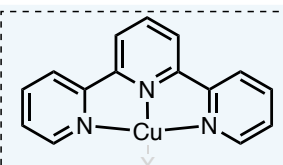

(Cu)

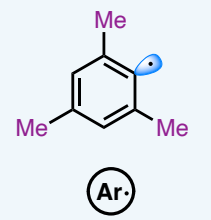

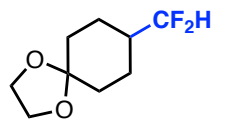

$13,90 \%{ }^{b}$<smiles>CC(C)[C@H]1CC[C@@H](C)C[C@H]1C(F)(F)F</smiles>

$18,51 \%^{b}$, d.r. $=16: 1$

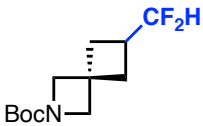

23, $51 \%$<smiles>CC(Cc1ccccc1)C(F)(F)F</smiles>

$28,62 \%^{b}$<smiles>Cc1ccc(S(=O)(=O)N2CCCC2CC(F)F)cc1</smiles>

33, $75 \%$<smiles>FC(F)(F)CCc1ccc(I)cc1</smiles>

$38,59 \%$<smiles></smiles>

43, $42 \%$<smiles>FC(F)(F)C1COC([Pb])OC1</smiles>

$14,78 \%$, d.r. $=3: 1^{c}$ (54\% major isomer)

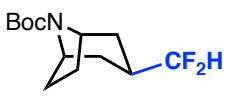

$19,80 \%$, d.r. $=5: 1^{c}$ (62\% major isomer)

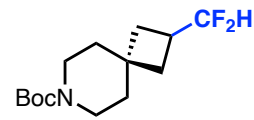

24, $52 \%$<smiles>CC(C)(C)OC(=O)N1CCC(CC(F)(F)C(C)(C)F)CC1</smiles>

$29,88 \%$<smiles>O=C1c2ccccc2C(=O)N1CCCC(F)F</smiles>

34, $76 \%$<smiles>Oc1ccc(CCC=[Fe])cc1</smiles>

$39,92 \%$

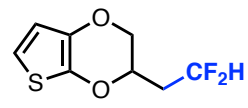

$44,69 \%$<smiles>O=C(c1ccccc1)N1CCC([SeH+])CC1</smiles>

$15,65 \%$<smiles>[CH2]C1CCN(Cc2ccccc2)CC1</smiles>

20, $79 \%$<smiles>[CH+]C(CCCCCC)CCCCCCCCCC</smiles>

$25,60 \%$

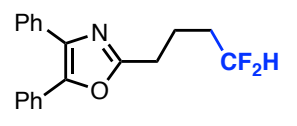

$45,68 \%$<smiles>O=C(NC1CCC(C(F)(F)F)CC1)Oc1ccccc1</smiles>

$17,73 \%$ d.r. $=1: 1$<smiles>COC(=O)C1CC(C(F)(F)F)CN1C(=O)OCc1ccccc1</smiles>

21, $54 \%$, d.r. $=2.1: 1$<smiles>CC(CNC(=O)OCc1ccccc1)C(F)(F)F</smiles><smiles>COC(=O)N[C@@H](C(=O)OC)C(C)C(F)F</smiles>

27, $70 \%$, d.r. $=1.2: 1$<smiles></smiles><smiles>COC(=O)C(CC(F)(F)F)NC(=O)OC(C)(C)C</smiles>

$31,69 \%$<smiles>FC(F)(F)CCC(F)(F)C(F)(F)C(F)(F)C(F)(F)C(F)(F)C(F)(F)F</smiles>

$35,56 \%^{b}$<smiles>O=Cc1ccc(OCCC(F)F)cc1</smiles>

$40,91 \%^{b}$

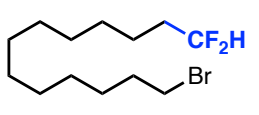

$36,67 \%$<smiles>COc1cc(CCCC(F)F)cc(OC)c1OC</smiles>

41, $85 \%$<smiles>O=C(F)NCCCC(F)(F)F</smiles>

32, $77 \%, 65 \%$ (5 mmol)<smiles>FC(F)(F)CCc1ccccc1Br</smiles>

$37,82 \%$

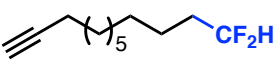

42, $49 \%$

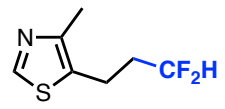

46, $46 \%{ }^{b}$<smiles>FC(F)(F)CCOc1nc(Cl)c(Cl)cc1Cl</smiles>

$47,66 \%$

${ }^{a}$ Reactions were run with $0.25 \mathrm{mmol}$ of alkyl iodides, $0.625 \mathrm{mmol}$ of $\mathbf{4 a}$ (2.5 equiv.), $0.375 \mathrm{mmol}$ of $\mathbf{1}$ (1.5 equiv.), L1 (20 mol \%) and $\mathrm{Cu}(\mathrm{OTf})_{2}(20 \mathrm{~mol} \%)$ in $1.5 \mathrm{~mL}$ of DMSO at r.t. under Ar. Isolated yields were reported. ${ }^{b}$ Yield determined by ${ }^{19} \mathrm{~F}$ NMR due to the volatility of the product. ${ }^{\mathrm{C} Y i e l d}$ and diastereoselectivity determined by ${ }^{19} \mathrm{~F}$ NMR of the crude reaction mixture. Isolated yield of the major isomer shown in parenthesis. 
Table 3. Copper-Catalyzed Late-Stage Difluoromethylation of Complex Bio-Relevant Molecules ${ }^{\mathrm{a}}$

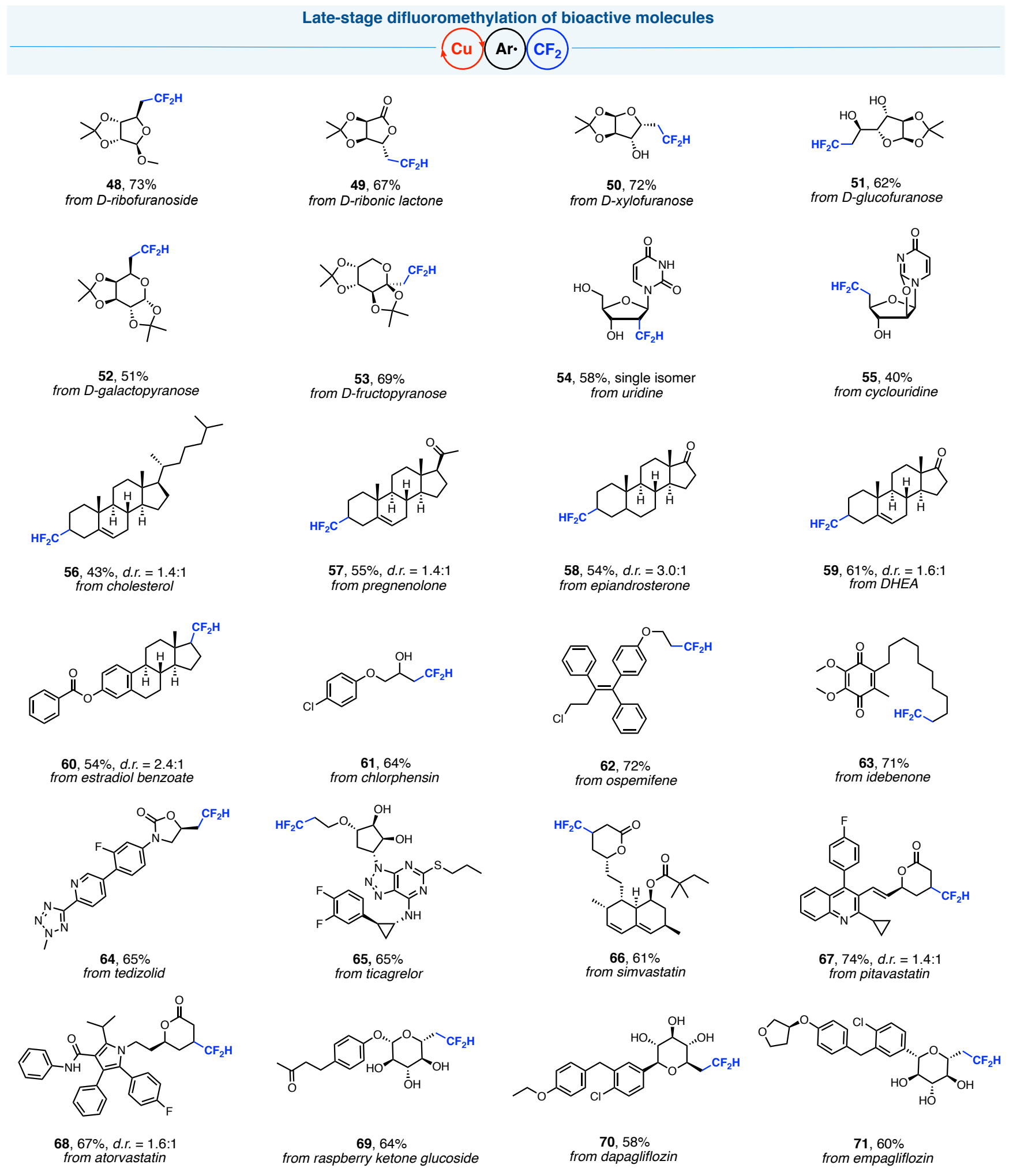

${ }^{a}$ Reactions were run with $0.25 \mathrm{mmol}$ of alkyl iodides, $0.625 \mathrm{mmol}$ of diazonium salt (2.5 equiv.), $0.375 \mathrm{mmol}$ of $\mathbf{1}$ (1.5 equiv.), L1 $(20 \mathrm{~mol} \%)$ and $\mathrm{Cu}(\mathrm{OTf})_{2}(20 \mathrm{~mol} \%)$ in $1.5 \mathrm{~mL}$ of DMSO at r.t. under Ar. Isolated yields were reporte 


\section{Late-Stage Difluoromethylation of Bioactive Molecules}

Alkyl iodides could be easily synthesized via Appel iodination reactions from alcohols, which are ubiquitous in natural products and pharmaceutical agents, such as carbohydrates, nucleosides, steroids, and glycosides. Thus, the synthetic utility of this difluoromethylation protocol was further highlighted by the late-stage functionalization of a large variety of alkyl halides derived from complex bio-relevant molecules (Table 3). Alkyl iodides prepared from a group of commercially available monosaccharides (ribose, xylose, glucose, galactose, and fructose), some of which contained unprotected hydroxyl groups, could readily couple with the $\mathrm{CF}_{2} \mathrm{H}$ groups to afford the desired difluoromethylated carbohydrates (48 to 53, 51 to $73 \%$ yield). Additionally, fluorine-containing nucleosides have shown desired properties as antiviral and antitumor agents, but their preparation usually required multi-step synthesis. ${ }^{86,} 87$ Gratifyingly, with our protocol, two $\mathrm{CF}_{2} \mathrm{H}$-derivatives of uridine, a pyrimidine nucleoside, could be straightforwardly synthesized from the corresponding alkyl iodide precursors $(\mathbf{5 4}$ and $\mathbf{5 5}, 58$ and $40 \%$ yield, respectively). It is worthy of mention that compound 54 was previously prepared via a 7-step procedure, which involved tedious protection/deprotection steps as well as a preparative HPLC separation of the diastereomers. ${ }^{88}$ Moreover, a diverse range of steroids, including cholesterol, pregnenolone, androsterone, DHEA, and estradiol, were converted to their $\mathrm{CF}_{2} \mathrm{H}$ analogues in useful to good yields (56 to $60,43 \%$ to $61 \%$ yield).

In addition to natural-occurring compounds, pharmaceutical agents such as chlorphenesin, a muscle relaxant, ${ }^{89}$ and ospemifene, a selective estrogen receptor modulator, ${ }^{90}$ were successfully converted to their difluoromethylated analogues (61 and $\mathbf{6 2}, 64 \%$ and $72 \%$ yield, respectively). These two examples demonstrated the compatibility of aryl and alkyl chloride bonds with this approach. Idebenone, a benzoquinone-containing molecule that was originally designed for the treatment of cognitive defects, ${ }^{91}$ could be difluoromethylated with the benzoquinone group unaffected (63, 71\% yield). Tedizolid, an antibiotic that incorporated a tetrazole, a pyridine, and an oxazolidone ring, ${ }^{92}$ was transformed in good efficiency $(\mathbf{6 4}, 65 \%$ yield). Ticagrelor, a top-selling blood thinner ${ }^{93}$ that consisted of a diol, a thioether, a secondary amine and a triazolo $[4,5,-d]$ pyrimidine scaffold, was converted to its $\mathrm{CF}_{2} \mathrm{H}$ analogue in a $65 \%$ yield $(65)$. Three cholesterol-lowering statins, including simvastatin, pitavastatin, and atorvastatin, all produced the desired $\mathrm{CF}_{2} \mathrm{H}$ products in good yields (66 to $68,61 \%$ to $74 \%$ yield). It is noteworthy that the stereoisomers of these $\mathrm{CF}_{2} \mathrm{H}$-lactones could be easily separated via silica column chromatography, thus potentially enabling structure-activity relationship studies. Finally, this protocol was applied to the difluoromethylation of glucoside compounds, including raspberry ketone glucoside (69, 64\% yield), dapagliflozin (70, 58\% yield) and empagliflozin (71, 60\% yield), the latter two of which were among the top-selling pharmaceuticals in 2020 for the treatment of diabetes. ${ }^{94}$ The tolerance of unprotected triol groups further highlighted the mild conditions of the aryl radical activation strategy. Considering that $\mathrm{CF}_{2} \mathrm{H}$ groups could serve as the bioisoteres of hydroxyl groups, this difluoromethylation approach should enable the rapid synthesis and evaluation of bioisoteres of drug candidates.

\section{Mechanistic Studies.}

To further shed light on this aryl radical-enabled, copper-catalyzed protocol, we conducted several mechanistic studies to support the proposed catalytic cycle (Figure 3). The coupling of a cyclopropyl-containing alkyl iodide $\mathbf{7 2}$ under the standard conditions afforded mainly the ring-opened product $\mathbf{7 3}$, with trace amounts of unrearranged product 74. This result supports the presence of alkyl radicals in the reactions (Figure 3a).

Moreover, the addition of TEMPO (2 equiv.), a radical trapping agent, to the coupling of $\mathbf{1 2}$ led to the suppression of the formation of 13, while the TEMPO adduct $\mathbf{7 5}$ was isolated in a $55 \%$ yield (Figure $\mathbf{3 b}$ ). The formation of $\mathbf{7 5}$ further supports the involvement of an alkyl radical intermediate. More importantly, the failure of TEMPO to directly trap the aryl radical was consistent with the high reaction rate of the iodine abstraction step. Finally, GC analysis of the reaction mixture demonstrated that iodomesitylene $\mathbf{7 6}$ was formed in a nearly quantitative yield, in agreement with the aryl radical abstracting an iodine atom from an alkyl iodide (Figure 3c).

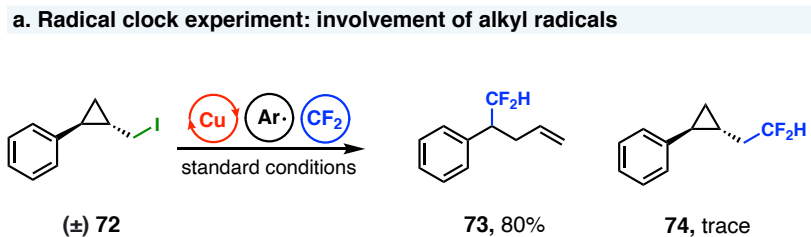

b. TEMPO trapping experiment: facile iodine abstraction

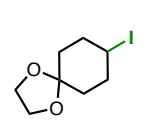

12

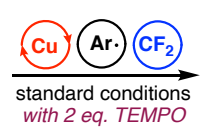

with 2 eq. TEMPO

13 , trace

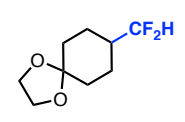

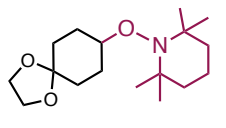

$75,55 \%$ c. Formation of aryl iodide: aryl radical activation pathway<smiles>IC1CCC2(CC1)OCCO2</smiles>

12

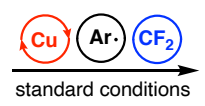

$\underset{\text { tandard conditions }}{\longrightarrow}$

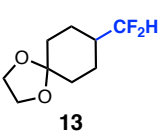

3

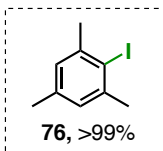

Figure 3. Mechanistic studies support the proposed aryl radical activation mechanism.

Overall, these mechanistic studies support the hypothetical mechanism in which the iodine abstraction from an alkyl iodide by an aryl radical was involved. In addition, the successful execution of the aryl radical activation strategy could be attributed to the fast iodine abstraction by aryl radicals. More thorough mechanistic studies are currently ongoing in our laboratory to better understand this aryl radical activation strategy. 


\section{CONCLUSION}

To conclude, the century-old Sandmeyer reactions have taught the synthetic community one of the simplest ways of generating of aryl radicals. However, the reactivity of aryl radicals that received attention in synthetic chemistry was limited to either nucleophilic substitutions or the addition to unsaturated bonds. We report herein an aryl radical activation strategy that harnesses the halogen abstraction ability of aryl radicals, thus allowing unactivated alkyl iodides to participate in copper-catalyzed Negishi-type cross-coupling reactions. This aryl radical-enabled difluoromethylation reaction demonstrated high functional group tolerance and empowered late-stage modification of complex bioactive molecules. Mechanistic studies indicated that the rapid iodine atom abstraction by aryl radicals contributed the success of this strategy. Given the rich medicinal potential of $\mathrm{CF}_{2} \mathrm{H}$ groups and the broad availability of alkyl halides, we anticipate that this protocol will find wide application in drug development. Most important, we expect that this aryl radical activation strategy will be a general paradigm to the development of a diverse range of $\mathrm{C}-\mathrm{C}$ and $\mathrm{C}-$ heteroatom bond-forming reactions.

\section{Acknowledgements}

W.L. acknowledges financial support from the University of Cincinnati. NMR experiments were performed using a Bruker AVANCE NEO $400 \mathrm{MHz}$ NMR spectrometer (funded by NSFMRI grant CHE-1726092).

Keywords: Difluoromethylation • Copper Catalysis • Aryl Radical $\bullet$ Cross Coupling $\bullet$ Alkyl Halides

\section{REFERENCES}

1. Lovering, F., Escape from Flatland 2: complexity and promiscuity. MedChemComm 2013, 4 (3), $515-519$.

2. Lovering, F.; Bikker, J.; Humblet, C., Escape from Flatland: Increasing Saturation as an Approach to Improving Clinical Success. J. Med. Chem. 2009, 52 (21), 6752-6756.

3. Armin de Meijere, S. B., Martin Oestreich, Metal - Catalyzed Cross - Coupling Reactions and More, 1, 2 and 3. Wiley - VCH, 2014: 2013.

4. Diederich, F. o.; Stang, P. J., Metal-catalyzed cross-coupling reactions. Wiley-VCH: New York, 1998 ; p xxi, 517

5. $\quad$ Choi, J.; Fu, G. C., Transition metal-catalyzed alkyl-alkyl bond formation: Another dimension in cross-coupling chemistry. Science 2017, 356 (6334), eaaf7230.

6. Rudolph, A.; Lautens, M., Secondary Alkyl Halides in Transition-Metal-Catalyzed Cross-Coupling Reactions. Angew. Chem. Int. Ed. 2009, 48 (15), 2656-2670.

7. Hazari, N.; Melvin, P. R.; Beromi, M. M., Well-defined nickel and palladium precatalysts for cross-coupling. Nat. Rev. Chem. 2017, 1 (3), 0025.

8. Miyaura, N.; Suzuki, A., Palladium-Catalyzed Cross-Coupling Reactions of Organoboron Compounds. Chem. Rev. 1995, 95 (7), 2457-2483.

9. Hickman, A. J.; Sanford, M. S., High-valent organometallic copper and palladium in catalysis. Nature 2012, 484, 177.

10. Beletskaya, I. P.; Cheprakov, A. V., The Heck Reaction as a Sharpening Stone of Palladium Catalysis. Chem. Rev. 2000, 100 (8), 3009-3066.

11. Tasker, S. Z.; Standley, E. A.; Jamison, T. F., Recent advances in homogeneous nickel catalysis. Nature 2014, 509 (7500), 299-309.

12. Tellis, J. C.; Kelly, C. B.; Primer, D. N.; Jouffroy, M.; Patel, N. R.; Molander, G. A., Single-Electron

Transmetalation via Photoredox/Nickel Dual Catalysis: Unlocking a New Paradigm for sp(3)-sp(2) Cross-Coupling. Acc. Chem. Res. 2016, 49 (7), 1429-1439.

13. Diccianni, J. B.; Diao, T. N., Mechanisms of Nickel-Catalyzed Cross-Coupling Reactions. Trends Chem 2019,1 (9), 830-844.

14. Qin, T.; Cornella, J.; Li, C.; Malins, L. R.; Edwards, J. T.; Kawamura, S.; Maxwell, B. D.; Eastgate, M. D.; Baran, P. S., A general alkyl-alkyl cross-coupling enabled by redox-active esters and alkylzinc reagents. Science 2016, 352 (6287), 801.

15. Merchant, R. R.; Edwards, J. T.; Qin, T.; Kruszyk, M. M.; Bi, C.; Che, G.; Bao, D.-H.; Qiao, W.; Sun, L.; Collins, M. R.; Fadeyi, O. O.; Gallego, G. M.; Mousseau, J. J.; Nuhant, P.; Baran, P. S., Modular radical crosscoupling with sulfones enables access to sp3-rich (fluoro)alkylated scaffolds. Science 2018, 360 (6384), 75.

16. Tsarevsky, N. V.; Matyjaszewski, K., "Green" Atom Transfer Radical Polymerization: From Process Design to Preparation of Well-Defined Environmentally Friendly Polymeric Materials. Chem. Rev. 2007, 107 (6), $2270-2299$.

17. Matyjaszewski, K.; Tsarevsky, N. V., Macromolecular Engineering by Atom Transfer Radical Polymerization. J. Am. Chem. Soc. 2014, 136 (18), 6513-6533. 
18. McCann, S. D.; Stahl, S. S., Copper-Catalyzed Aerobic Oxidations of Organic Molecules: Pathways for TwoElectron Oxidation with a Four-Electron Oxidant and a One-Electron Redox-Active Catalyst. Acc. Chem. Res. 2015, 48 (6), 1756-1766.

19. Hossain, A.; Bhattacharyya, A.; Reiser, O., Copper's rapid ascent in visible-light photoredox catalysis. Science 2019, 364 (6439), eaav9713.

20. Thapa, S.; Shrestha, B.; Gurung, S. K.; Giri, R., Copper-catalysed cross-coupling: an untapped potential. Org. Biomol. Chem. 2015, 13 (17), 4816-4827.

21. Trammell, R.; Rajabimoghadam, K.; Garcia-Bosch, I., Copper-Promoted Functionalization of Organic Molecules: from Biologically Relevant Cu/O2 Model Systems to Organometallic Transformations. Chem. Rev. 2019, 119 (4), 2954-3031.

22. Egorova, K. S.; Ananikov, V. P., Which Metals are Green for Catalysis? Comparison of the Toxicities of Ni, Cu, Fe, Pd, Pt, Rh, and Au Salts. Angew. Chem. Int. Ed. 2016, 55 (40), 12150-12162.

23. Egorova, K. S.; Ananikov, V. P., Toxicity of Metal Compounds: Knowledge and Myths. Organometallics 2017, 36 (21), 4071-4090.

24. Cheng, L.-J.; Mankad, N. P., C-C and C-X coupling reactions of unactivated alkyl electrophiles using copper catalysis. Chem. Soc. Rev. 2020, 49 (22), 8036-8064.

25. $\quad$ sigmaaldrich.com, accessed June 2021

26. Festa, R. A.; Thiele, D. J., Copper: An essential metal in biology. Curr. Biol. 2011, 21 (21), R877-R883.

27. Solomon, E. I.; Heppner, D. E.; Johnston, E. M.; Ginsbach, J. W.; Cirera, J.; Qayyum, M.; Kieber-Emmons, M. T.; Kjaergaard, C. H.; Hadt, R. G.; Tian, L., Copper Active Sites in Biology. Chem. Rev. 2014,114 (7), $3659-3853$.

28. Solomon, E. I.; Hadt, R. G., Recent advances in understanding blue copper proteins. Coord. Chem. Rev. 2011, 255 (7), 774-789.

29. Peterson, R. L.; Galaleldeen, A.; Villarreal, J.; Taylor, A. B.; Cabelli, D. E.; Hart, P. J.; Culotta, V. C., The Phylogeny and Active Site Design of Eukaryotic Copper-only Superoxide Dismutases*. J. Biol. Chem. 2016, 291 (40), 20911-20923.

30. "Elemental Impurities in Drug Products Guidance for Industry", United States Food and Drug Administration, August 2018

31. Chen, C.; Peters, J. C.; Fu, G. C., Photoinduced copper-catalysed asymmetric amidation via ligand cooperativity. Nature 2021.

32. Creutz, S. E.; Lotito, K. J.; Fu, G. C.; Peters, J. C., Photoinduced Ullmann C-N Coupling: Demonstrating the Viability of a Radical Pathway. Science 2012, 338 (6107), 647.

33. Bissember, A. C.; Lundgren, R. J.; Creutz, S. E.; Peters, J. C.; Fu, G. C., Transition-Metal-Catalyzed Alkylations of Amines with Alkyl Halides: Photoinduced, Copper-Catalyzed Couplings of Carbazoles. Angew. Chem. Int. Ed. 2013, 52 (19), 5129-5133.

34. Kainz, Q. M.; Matier, C. D.; Bartoszewicz, A.; Zultanski, S. L.; Peters, J. C.; Fu, G. C., Asymmetric coppercatalyzed C-N cross-couplings induced by visible light. Science 2016, 351 (6274), 681.

35. Hazra, A.; Lee, M. T.; Chiu, J. F.; Lalic, G., Photoinduced Copper-Catalyzed Coupling of Terminal Alkynes and Alkyl lodides. Angew. Chem. Int. Ed. 2018, 57 (19), 5492-5496.

36. Le, C.; Chen, T. Q.; Liang, T.; Zhang, P.; MacMillan, D. W. C., A radical approach to the copper oxidative addition problem: Trifluoromethylation of bromoarenes. Science 2018, 360 (6392), 1010.

37. Kornfilt, D. J. P.; MacMillan, D. W. C., Copper-Catalyzed Trifluoromethylation of Alkyl Bromides. J. Am. Chem. Soc. 2019, 141 (17), 6853-6858.

38. Zhao, X.; MacMillan, D. W. C., Metallaphotoredox Perfluoroalkylation of Organobromides. J. Am. Chem. Soc. 2020, 142 (46), 19480-19486.

39. Górski, B.; Barthelemy, A.-L.; Douglas, J. J.; Juliá, F.; Leonori, D., Copper-catalysed amination of alkyl iodides enabled by halogen-atom transfer. Nat. Cat. 2021, 4 (7), 623-630.

40. Constantin, T.; Zanini, M.; Regni, A.; Sheikh, N. S.; Juliá, F.; Leonori, D., Aminoalkyl radicals as halogenatom transfer agents for activation of alkyl and aryl halides. Science 2020, 367 (6481), 1021.

41. Galli, C., Radical reactions of arenediazonium ions: An easy entry into the chemistry of the aryl radical. Chem. Rev. 1988, 88 (5), 765-792.

42. Dolenc, D.; Plesničar, B., Abstraction of lodine from Aromatic lodides by Alkyl Radicals: Steric and Electronic Effects. J. Org. Chem. 2006, 71 (21), 8028-8036.

43. Luo, Y.-R.; Luo, Y.-R., Comprehensive handbook of chemical bond energies. CRC Press: Boca Raton, 2007; $p$ $1655 \mathrm{p}$.

44. Heinrich, M. R., Intermolecular Olefin Functionalisation Involving Aryl Radicals Generated from Arenediazonium Salts. Chem. Eur. J. 2009, 15 (4), 820-833.

45. Tatunashvili, E.; McErlean, C. S. P., Generation and reaction of alkyl radicals in open reaction vessels. Org. Biomol. Chem. 2020, 18 (39), 7818-7821. 
46. Chaambi, A.; Kurtay, G.; Abderrahim, R.; Robert, F.; Landais, Y., Aryl Radical-Mediated Alkenylation of Alkyl Halides. Helv Chim Acta 2019, 102 (8).

47. Kurandina, D.; Yadagiri, D.; Rivas, M.; Kavun, A.; Chuentragool, P.; Hayama, K.; Gevorgyan, V., TransitionMetal- and Light-Free Directed Amination of Remote Unactivated C(sp3)-H Bonds of Alcohols. J. Am. Chem. Soc. 2019, 141 (20), 8104-8109.

48. Mo, F.; Qiu, D.; Zhang, L.; Wang, J., Recent Development of Aryl Diazonium Chemistry for the Derivatization of Aromatic Compounds. Chem. Rev. 2021.

49. Erickson, J. A.; McLoughlin, J. I., Hydrogen Bond Donor Properties of the Difluoromethyl Group. J. Org. Chem. 1995, 60 (6), 1626-1631.

50. Sessler, C. D.; Rahm, M.; Becker, S.; Goldberg, J. M.; Wang, F.; Lippard, S. J., CF2H, a Hydrogen Bond Donor. J. Am. Chem. Soc. 2017, 139 (27), 9325-9332.

51. Yerien, D. E.; Barata-Vallejo, S.; Postigo, A., Difluoromethylation Reactions of Organic Compounds. Chem. Eur. J. 2017, 23 (59), 14676-14701.

52. Rong, J.; Ni, C.; Hu, J., Metal-Catalyzed Direct Difluoromethylation Reactions. Asia. J. Org. Chem. 2017, 6 (2), 139-152.

53. Lu, Y.; Liu, C.; Chen, Q. Y., Recent Advances in Difluoromethylation Reaction. Curr. Org. Chem. 2015, 19 (16), 1638-1650.

54. Belhomme, M.-C.; Besset, T.; Poisson, T.; Pannecoucke, X., Recent Progress toward the Introduction of Functionalized Difluoromethylated Building Blocks onto C(sp2) and C(sp) Centers. Chem. Eur. J. 2015, 21 (37), 1283612865.

55. Feng, Z.; Xiao, Y.-L.; Zhang, X., Transition-Metal (Cu, Pd, Ni)-Catalyzed Difluoroalkylation via Cross-Coupling with Difluoroalkyl Halides. Acc. Chem. Res. 2018, 51 (9), 2264-2278.

56. Sap, J. B. I.; Meyer, C. F.; Straathof, N. J. W.; Iwumene, N.; am Ende, C. W.; Trabanco, A. A.; Gouverneur, V., Late-stage difluoromethylation: concepts, developments and perspective. Chem. Soc. Rev. 2021, 50 (14), $8214-$ 8247.

57. Carvalho, D. R.; Christian, A. H., Modern approaches towards the synthesis of geminal difluoroalkyl groups. Org. Biomol. Chem. 2021, 19 (5), 947-964.

58. Zafrani, Y.; Sod-Moriah, G.; Yeffet, D.; Berliner, A.; Amir, D.; Marciano, D.; Elias, S.; Katalan, S.; Ashkenazi, N.; Madmon, M.; Gershonov, E.; Saphier, S., CF2H, a Functional Group-Dependent Hydrogen-Bond Donor: Is It a More or Less Lipophilic Bioisostere of $\mathrm{OH}, \mathrm{SH}$, and CH3? J. Med. Chem. 2019, 62 (11), 5628-5637. 59. Zafrani, Y.; Yeffet, D.; Sod-Moriah, G.; Berliner, A.; Amir, D.; Marciano, D.; Gershonov, E.; Saphier, S., Difluoromethyl Bioisostere: Examining the "Lipophilic Hydrogen Bond Donor" Concept. J. Med. Chem. 2017, 60 (2), 797-804.

60. Zafrani, Y.; Saphier, S.; Gershonov, E., Utilizing the CF2H moiety as a H-bond-donating group in drug discovery. Future Med. Chem. 2020, 12 (5), 361-365.

61. Xu, C.; Guo, W.-H.; He, X.; Guo, Y.-L.; Zhang, X.-Y.; Zhang, X., Difluoromethylation of (hetero)aryl chlorides with chlorodifluoromethane catalyzed by nickel. Nat. Commun. 2018, 9 (1), 1170.

62. Xu, L.; Vicic, D. A., Direct Difluoromethylation of Aryl Halides via Base Metal Catalysis at Room Temperature. J. Am. Chem. Soc. 2016, 138 (8), 2536-2539.

63. Aikawa, K.; Serizawa, H.; Ishii, K.; Mikami, K., Palladium-Catalyzed Negishi Cross-Coupling Reaction of Aryl Halides with (Difluoromethyl)zinc Reagent. Org. Lett. 2016, 18 (15), 3690-3693.

64. Serizawa, H.; Ishii, K.; Aikawa, K.; Mikami, K., Copper-Catalyzed Difluoromethylation of Aryl lodides with (Difluoromethyl)zinc Reagent. Org. Lett. 2016, 18 (15), 3686-3689.

65. Lu, C.; Gu, Y.; Wu, J.; Gu, Y.; Shen, Q., Palladium-catalyzed difluoromethylation of heteroaryl chlorides, bromides and iodides. Chem. Sci. 2017, 8 (7), 4848-4852.

66. Gu, Y.; Leng, X.; Shen, Q., Cooperative dual palladium/silver catalyst for direct difluoromethylation of aryl bromides and iodides. Nat. Commun. 2014, 5, 5405.

67. Fier, P. S.; Hartwig, J. F., Copper-Mediated Difluoromethylation of Aryl and Vinyl lodides. J. Am. Chem. Soc. 2012, 134 (12), 5524-5527.

68. $\quad$ Bacauanu, V.; Cardinal, S.; Yamauchi, M.; Kondo, M.; Fernández, D. F.; Remy, R.; MacMillan, D. W. C., Metallaphotoredox Difluoromethylation of Aryl Bromides. Angew. Chem. Int. Ed. 2018, 57 (38), 12543-12548.

69. Bour, J. R.; Kariofillis, S. K.; Sanford, M. S., Synthesis, Reactivity, and Catalytic Applications of Isolable (NHC)Cu(CHF2) Complexes. Organometallics 2017, 36 (7), 1220-1223.

70. Prakash, G. K. S.; Hu, J.; Wang, Y.; Olah, G. A., Nucleophilic Difluoromethylation of Primary Alkyl Halides Using Difluoromethyl Phenyl Sulfone as a Difluoromethyl Anion Equivalent. Org. Lett. 2004, 6 (23), 4315-4317.

71. Zhao, H.; Lu, C.; Herbert, S.; Zhang, W.; Shen, Q., Difluoromethylation of Alkyl Bromides and lodides with TMSCF2H. J. Org. Chem. 2021, 86 (3), 2854-2865.

72. Monfette, S.; Fang, Y.-Q.; Bio, M. M.; Brown, A. R.; Crouch, I. T.; Desrosiers, J.-N.; Duan, S.; Hawkins, J. M.; Hayward, C. M.; Peperni, N.; Rainville, J. P., Continuous Process for Preparing the Difluoromethylating Reagent 
[(DMPU)2Zn(CF2H)2] and Improved Synthesis of the ICHF2 Precursor. Org. Process Res. Dev. 2020, 24 (6), 10771083.

73. Zeng, X.; Yan, W.; Zacate, S. B.; Cai, A.; Wang, Y.; Yang, D.; Yang, K.; Liu, W., Copper-Catalyzed Deaminative Difluoromethylation. Angew. Chem. Int. Ed. 2020, 59 (38), 16398-16403.

74. Zeng, X. J.; Yan, W. H.; Zacate, S. B.; Chao, T. H.; Sun, X. D.; Cao, Z.; Bradford, K. G. E.; Paeth, M.; Tyndall, S. B.; Yang, K. D.; Kuo, T. C.; Cheng, M. J.; Liu, W., Copper-Catalyzed Decarboxylative Difluoromethylation. J. Am. Chem. Soc. 2019, 141 (29), 11398-11403.

75. Zeng, X. J.; Yang, W. H.; Paeth, M.; Zacate, S. B.; Hong, P. H.; Wang, Y. F.; Yang, D. Q.; Yang, K. D.; Yan, T.; Song, C.; Cao, Z.; Cheng, M. J.; Liu, W., Copper-Catalyzed, Chloroamide-Directed Benzylic C-H Difluoromethylation. J. Am. Chem. Soc. 2019, 141 (50), 19941-19949.

76. Matheis, C.; Jouvin, K.; Goossen, L. J., Sandmeyer Difluoromethylation of (Hetero-)Arenediazonium Salts. Org. Lett. 2014, 16 (22), 5984-5987.

77. Cai, A.; Yan, W.; Zeng, X.; Zacate, S. B.; Chao, T.-H.; Krause, J. A.; Cheng, M.-J.; Liu, W., Coppercatalyzed carbo-difluoromethylation of alkenes via radical relay. Nat. Commun. 2021, 12 (1), 3272.

78. Cai, A.; Yan, W.; Liu, W., Aryl Radical Activation of C-O Bonds: Copper-Catalyzed Deoxygenative Difluoromethylation of Alcohols. J. Am. Chem. Soc. 2021, 143 (26), 9952-9960.

79. DiMucci, I. M.; Lukens, J. T.; Chatterjee, S.; Carsch, K. M.; Titus, C. J.; Lee, S. J.; Nordlund, D.; Betley, T. A.; MacMillan, S. N.; Lancaster, K. M., The Myth of d8 Copper(III). J. Am. Chem. Soc. 2019, 141 (46), 18508-18520.

80. Lu, Z.; Liu, H.; Liu, S.; Leng, X.; Lan, Y.; Shen, Q., A Key Intermediate in Copper-Mediated Arene Trifluoromethylation, [nBu4N][Cu(Ar)(CF3)3]: Synthesis, Characterization, and C(sp2)-CF3 Reductive Elimination. Angew. Chem. Int. Ed. 2019, 58 (25), 8510-8514.

81. Liu, S.; Liu, H.; Liu, S.; Lu, Z.; Lu, C.; Leng, X.; Lan, Y.; Shen, Q., C(sp3)-CF3 Reductive Elimination from a Five-Coordinate Neutral Copper(III) Complex. J. Am. Chem. Soc. 2020, 142 (21), 9785-9791.

82. Paeth, M.; Tyndall, S. B.; Chen, L.-Y.; Hong, J.-C.; Carson, W. P.; Liu, X.; Sun, X.; Liu, J.; Yang, K.; Hale, E. M.; Tierney, D. L.; Liu, B.; Cao, Z.; Cheng, M.-J.; Goddard, W. A.; Liu, W., Csp3-Csp3 Bond-Forming Reductive Elimination from Well-Defined Copper(III) Complexes. J. Am. Chem. Soc. 2019, 141 (7), 3153-3159.

83. Bunnett, J. F.; Wamser, C. C., Radical Abstraction of lodine from Aryl lodides. J. Am. Chem. Soc. 1966, 88 (23), 5534-\&.

84. Tanner, D. D.; Reed, D. W.; Setiloane, B. P., Polar Radicals .17. On the Mechanism of lodine Atom Transfer a 9-I-2 Intermediate. J. Am. Chem. Soc. 1982, 104 (14), 3917-3923.

85. Amaya, T.; Jin, Y.; Tobisu, M., Recent advances in Gomberg-Backmann biaryl synthesis. Tetrahedron Lett. 2019, 60 (39), 151062.

86. Qiu, X.-L.; Xu, X.-H.; Qing, F.-L., Recent advances in the synthesis of fluorinated nucleosides. Tetrahedron 2010, $66(4), 789-843$.

87. Cavaliere, A.; Probst, K. C.; Westwell, A. D.; Slusarczyk, M., Fluorinated nucleosides as an important class of anticancer and antiviral agents. Future Med. Chem. 2017, 9 (15), 1809-1833.

88. Serafinowski, P. J.; Brown, C. A., New Method For The Preparation Of $3^{\prime}$ - And 2' -O-Phosphoramidites Of $2^{\prime}$ - And 3' -Difluoromethyluridine Derivatives. Nucleosides, Nucleotides \& Nucleic Acids 2002, 21 (1), 1-13.

89. A New Skeletal Muscle Relaxant - Chlorphenesin Carbamate (Maolate). J Amer Med Assoc 1966, 196 (9), 783-\&.

90. Portman, D. J.; Bachmann, G. A.; Simon, J. A.; and the Ospemifene Study, G., Ospemifene, a novel selective estrogen receptor modulator for treating dyspareunia associated with postmenopausal vulvar and vaginal atrophy. Menopause 2013, 20 (6).

91. Gillis, J. C.; Benfield, P.; McTavish, D., Idebenone. Drugs \& Aging 1994, 5 (2), 133-152.

92. Zhanel, G. G.; Love, R.; Adam, H.; Golden, A.; Zelenitsky, S.; Schweizer, F.; Gorityala, B.; Lagacé-Wiens, P. R. S.; Rubinstein, E.; Walkty, A.; Gin, A. S.; Gilmour, M.; Hoban, D. J.; Lynch, J. P.; Karlowsky, J. A., Tedizolid: A Novel Oxazolidinone with Potent Activity Against Multidrug-Resistant Gram-Positive Pathogens. Drugs 2015, 75 (3), 253-270.

93. Wallentin, L.; Becker, R. C.; Budaj, A.; Cannon, C. P.; Emanuelsson, H.; Held, C.; Horrow, J.; Husted, S.; James, S.; Katus, H.; Mahaffey, K. W.; Scirica, B. M.; Skene, A.; Steg, P. G.; Storey, R. F.; Harrington, R. A., Ticagrelor versus Clopidogrel in Patients with Acute Coronary Syndromes. New Engl. J. Med. 2009, 361 (11), 10451057.

94. McGrath, N. A.; Brichacek, M.; Njardarson, J. T., A Graphical Journey of Innovative Organic Architectures That Have Improved Our Lives. J. Chem. Ed. 2010, 87 (12), 1348-1349. 
Aryl Radical Activation of Alkyl lodide for Copper-Catalyzed Cross Coupling

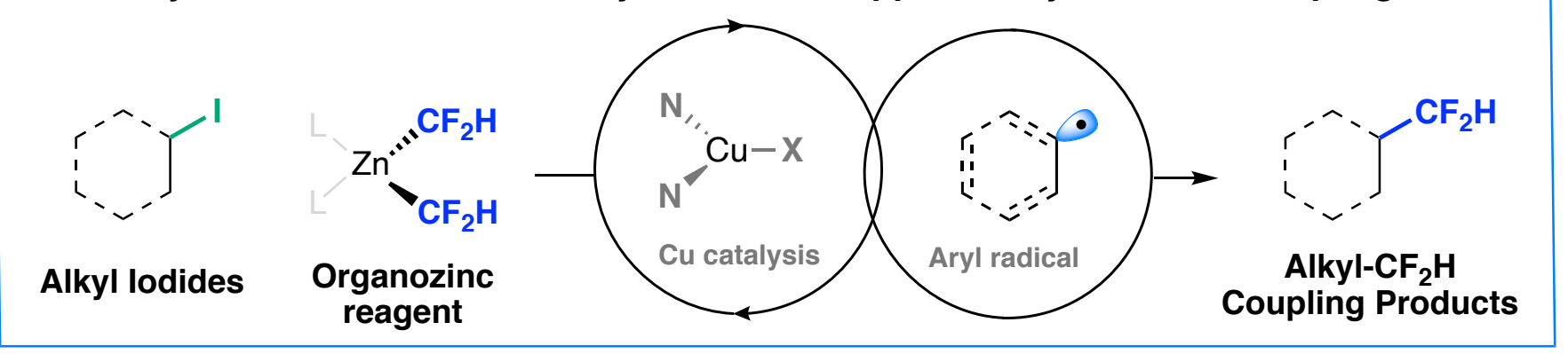

